\title{
The Four Strands of a Language Course
}

Paul Nation describes the main types of activity that should make up a balanced language course. These include meaning-focused listening and reading, language-focused instruction, meaning-focused speaking and writing, and fluency development activities.

$\mathrm{T}$ he aim of this paper is to apply recent research and theory in second language acquisition to the design of courses for learners of English, independent of any particular method of language teaching.

A basic assumption that lies behind this paper is that it is not wise for a teacher or course designer to ally themselves with a particular method of language teaching. It is much more productive to become aware of the important principles of teaching and learning, and to apply these in ways that suit the learners, the teaching

$65 .$. teaching and learning activities that have become unfashionable for a variety of reasons may still make a positive contribution to learning if they apply useful principles and if they are focused on worthwhile goals. 99 conditions and the skills of the teacher. This may result in courses that use different kinds of teaching and learning activities but which fundamentally draw on the same principles.

A related assumption is that teaching and learning activities that have become unfashionable for a variety of reasons may still make a positive contribution to learning if they apply useful principles and if they are focused on worthwhile goals. Thus, pronunciation practice, structure drills, learning words out of context, dictation activities and repetition activities performed in an appropriate way can contribute to one of the strands of a course. The trick lies in giving them a useful focus and a suitable amount of time.

\section{The four strands}

This paper suggests that a well-balanced language course should consist of four roughly equal strands:

1 Learning through meaning-focused input; that is, through listening and reading where the learners' attention is on the ideas and messages conveyed by the language.

2 Learning through deliberate attention to language items and language features; that is, through attention to the sounds and spelling of the language, through direct vocabulary study, through grammar exercises and explanation, and through deliberate attention to discourse features.

3 Learning through meaning-focused output; that is, through speaking and writing where the learners' attention is on conveying ideas and messages to another person.

4. Developing fluent use of known language items and features over the four skills of listening, speaking, reading and writing; that is, becoming fluent with what is already known.

A well-planned language course has an appropriate balance of these four strands.

It is through these strands that learners achieve the learning goals of a language course; namely fluent control of the sounds, spelling, vocabulary, grammar and discourse features of the language, so that they can be used to communicate effectively.

There is a tendency for language courses not to balance the four strands and, indeed, to give almost no attention to some of them. Courses which have a very strong communicative focus often actively discourage formal language-focused learning. There is no justification for this as second language acquisition research shows that appropriately focused attention to language items can make a very positive contribution to learning (Ellis 1990; Long 1988). At the other extreme, there are courses that seem to do little else but focus on formal features of the language with little or no opportunity to use what has been learned to receive and produce real messages. Perhaps even more commonly, there are courses that provide opportunity to receive and produce messages, that give useful attention to language features, but that do not provide opportunity for the learners to become truly fluent in using what they know. 
Let us now look at each of the four strands to see what justification there is for distinguishing it as a separate strand, the conditions that support learning, and some typical activities that set up the conditions for learning.

\section{Meaning-focused input}

Meaning-focused input consists of messages that the learner is likely to focus on mainly for the ideas that are contained in the message. It could include activities like listening to a story, taking part in a conversation, following instructions, or watching television.

Several writers (Krashen 1981; Newmark 1981; Taylor 1982; Terrell 1982) using different terminology see meaning-focused input as the major source of language learning, provided

${ }^{6}$ Language-focused instruction involves giving attention to features of the language not just for a particular message that they convey, but for their spoken or written form, their general meaning, the patterns that they fit into or their correct use.99 certain conditions for this learning through comprehension occurred. Newmark (1981: 39), for example says:

A comprehension approach can work ... as long as the material presented for comprehension in fact consists of (1) sufficient (2) language instances (3) whose meaning can be inferred by students (4) who are paying attention.

Terrell (1982) and Krashen (1981) would also add that the learner must not feel anxious or threatened by the situation.

The comprehension approach has its critics. Some such as Gregg (1984) criticise the logic and research evidence that the approach is based on. Others such as Swain (1985) suggest that it is not sufficient to result in the kind of learning that is needed to produce the language. All these critics, however, agree that language learning courses should contain substantial quantities of receptive activity. They consider that this receptive activity alone, however, is not sufficient for language learning.

In addition to being interested in the input and being able to understand most of it, some researchers would say that the new items in the input should be noticed by the learners, and if possible processed in ways requiring comparison with the learners' present knowledge, and creative use of the item. Creative use can be receptive and may involve meeting the item in new contexts, or having to rethink the significance of the item.

Typical activities to represent this strand of learning in a course are reading graded readers, listening to stories, taking part in or observing negotiated dialogue in information gap activities, and receptive information transfer activities (Palmer 1980).

In listening to stories, the teacher chooses a story that is suitable for the level of the learners and reads it to them so that they can enjoy the story. Any difficult words or constructions that occur are quickly explained and noted on the blackboard, without interrupting the story too much. The main focus is on the learners following and enjoying the story. If the story is a long story, like a graded reader, it can continue over several days, like a serial. The teacher should read the story at a reasonably slow pace making sure the learners are following. There should be frequent pauses to give the learners time to understand, and phrases or sentences can be repeated to make them clearer.

The emphasis in this strand is on the quality of enjoyable, understandable input.

\section{Language-focused learning}

Language-focused instruction involves giving attention to features of the language not just for a particular message that they convey, but for their spoken or written form, their general meaning, the patterns that they fit into, or their correct use. For example, the teacher may explain the meaning of a word to learners and show the pattern it fits into, or the learners may work through exercises based on a rule, such as add -ed to make the past tense.

There is now considerable evidence to show that language-focused instruction can help second language learning. Reviews by Long (1988) and Ellis (1990) suggest that language-focused instruction can have the following effects: 
1 A combination of language-focused instruction and meaning-focused instruction leads to better results than either kind of instruction alone.

2 Language-focused instruction can speed up the rate of second language acquisition.

3 Language-focused instruction may help learners to continue to improve their control of grammar rather than becoming stuck with certain errors.

4 Some language-focused instruction can lead directly to acquisition, depending on the kinds of items focused on.

5 Language-focused instruction can indirectly provide meaning-focused input.

There are, however, limitations on the effect of language-focused instruction. These limitations include the following:

1 Language-focused instruction cannot change the order in which learners acquire certain complex, developmental features of the language, such as questions, negatives, and relative clauses.

2 Language-focused instruction needs to be combined with the opportunity to use the same items in meaning-focused use.

3 Some items learned through language-focused instruction may only be available to the learner in planned use.

Language-focused learning contributes to language learning in three ways, one direct and two indirect. First, under certain conditions, it can add directly to implicit language knowledge through the explicit learning of new vocabulary, structures, and discourse features. Second, it can raise learners' awareness of certain language features so that they are more readily noticed in meaning-focused input, thus increasing the learning from meaning-focused input (Ellis 1993). Third, it can develop explicit knowledge of the language which can be used to add to implicit knowledge through carefully produced output becoming meaning-focused input, or through practice, although present research does not support the idea that practice can make explicit knowledge contribute to implicit knowledge.

\section{Meaning-focused output}

Some researchers argue that the knowledge that is needed to speak will not come unless the learners are 'pushed' to speak. Swain (1985) argues that learners can comprehend input without having to look closely at the grammar. If, however, they are pushed to produce output, then the attention that they give to the grammar changes; evidence to support this idea is beginning to appear (Ellis 1992).

\section{${ }^{66}$ Pushed output extends speakers o heightens their importance of atical features in of the language. ${ }^{99}$}

Learners are pushed when through encouragement or necessity they have to produce spoken language in unfamiliar areas. These areas may be unfamiliar because the learners are more used to listening or reading than speaking, or are not accustomed to speaking certain kinds of discourse, or are now expected to produce a higher standard of spoken language in terms of accuracy, precision, coherence and appropriateness. Pushed output extends speakers and in doing so heightens their awareness of the importance of particular grammatical features in productive use of the language.

The conditions required for language development through speaking and writing include the opportunity to retrieve previously met items (that is, not simply repeat them but recall the forms needed to express meanings), and the chance to use items in ways that are new to the user.

An elementary level meaning-focused speaking activity called speaking by numbers puts these conditions into practice. Each learner is given a number and a topic. The topics could include my family, money, coming to school, my hobby, trees, red etc. The learners can think about their topics for a minute or two and then the teacher calls a number. The learner with that number then says two or three sentences about his or her particular topic. Then that speaker calls a number and the learner with that number has to ask the speaker a question related to the topic just spoken about. When the question is answered, the questioner calls a number and the person with that number asks another question. This happens three or four times and then the teacher calls the number of the next person to speak about the topic that the new speaker was given. 
More advanced activities include role plays, problem solving activities, reading activities, and split information tasks.

\section{Fluency development activities}

Fluency has the following characteristics:

1 It involves "the processing of language in real

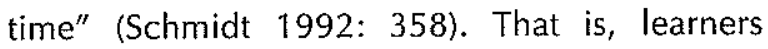
demonstrate fluency when they take part in meaning-focused activity and do it with speed and ease without holding up the flow of talk. There are observable signs that can be used to measure changes in fluency (Arevart and Nation 1991; Lennon 1990). These include speech rate (as measured in words or syllables per minute) (Griffiths 1991), number of filled pauses such as $u m$, ah, er, and a number of unfilled pauses.

2 The use of language does not require a great deal of attention and effort from the learner.

3 Fluency is a skill aspect of language use. Although it depends on quality of knowledge of the language, and its development involves the addition to, and restructuring of, knowledge, in essence it involves making the best possible use of what is already known.

Usually a distinction is made between fluency and accuracy and between activities that are designed to develop fluency and accuracy. This distinction is difficult to maintain. Nation (1989) and Arevart and Nation (1991) found that an activity that was designed to bring about an increase in fluency, also resulted in a reduction of errors and an increase in grammatical complexity. As the ease increases with which learners make use of what they know, then they are able to give more attention to the quality of what they use.

Schmidt's (1992) comprehensive review of the psychological mechanisms underlying second language fluency shows that it is not possible to account for developments in fluency simply through an increase in speed of processing. Substantial increases in fluency also involve changes in the nature of the knowledge of language. Anderson's (1989) $\mathrm{ACT}^{*}$ theory of skill development includes joining sequences into larger units, broadening the use of some rules, narrowing the scope of others, and strengthening those that are most effective. Cheng (1985: 367) sees restructuring as the essential feature underlying skilled performance. Restructuring involves changing the integration and organisation of knowledge components so that "the procedure involving the old components [is] replaced by a more effective procedure involving the new components." Even theories that see repeated practice as the major determinant of development see fluency as being related to a change in knowledge. It is, therefore, not surprising that developments in fluency are related to developments in accuracy.

Fluency is likely to develop if the following conditions are met:

1 The learners take part in activities where all the language items are within their previous experience. This means that the learners work with largely familiar topics and types of discourse making use of known vocabulary and structures.

2 The activity is meaning-focused. The learners' interest is on the communication of a message and is subject to the 'real time' pressures and demands of normal meaning-focused communication (Brumfit 1984: 56-57).

3 There is support and encouragement for the learner to perform at a higher than normal level. This means that in an activity with a fluency development goal, learners should be speaking and comprehending faster, hesitating less, and using larger planned chunks than they do in their normal use of language.

There need to be substantial opportunities for both receptive and productive language use where the goal is fluency. If the items that have been learned are not readily available for fluent use, then the learning has been for little purpose.

In the 4/3/2 technique (Maurice 1983), learners work in pairs with one acting as the speaker and the other as listener. The speaker talks for four minutes on a topic while the partner listens. Then the pairs change with each speaker giving the same information to a new partner in three minutes, followed by a further change and a two-minute talk.

From the point of view of fluency, this activity has these important features. First, the demands of the activity are limited to a much smaller set than would occur in most uncontrolled learning activities. 
This can be done by control by the teacher, as is the case in most receptive fluency activities such as reading graded readers or listening to stories, or can be done by choice, planning or repetition by the learner. In the $4 / 3 / 2$ activity the speaker chooses the ideas and language items, and plans the way of organising the talk. The 4- and 3-minute deliveries allow the speaker to bring these aspects well under control, so that fluency can become the learning goal of the activity. Note that the repetition of the talk is still with the learner's attention focused on the message because of the changing audience. Second, the speaker's attention is on getting the listener to understand what is being said. Third, the learner is

Another way of reaching a higher
than usual level of performance is
to work on the quality of the
performance. This can be done
through having an opportunity for
planning and preparation.

There are numerous ways of designing a planning and preparation element into listening and speaking activities. Here are some brief suggestions:

- brainstorming the topic;

- pre-reading on the topic;

- observation of others doing the activity;

- repeated opportunities to do the activity; in the first language; - prediction activities.

The purpose of the preparation is to make the quality of the listening or speaking reach a higher level than it would without the preparation.

helped to reach a high level of performance by having the opportunity to repeat, and by the challenge of decreasing time to convey the same message. Fourth, the user is encouraged to process a large quantity of language. In 4/3/2 this is done by allowing the speaker to perform without interruption and by having the speaker make three deliveries of the talk.

Another way of reaching a higher than usual level of performance is to work on the quality of the performance. This can be done through having an opportunity for planning and preparation. Crookes (1989) investigated learners who were given 10 minutes to plan what words, phrases and ideas they would use in their explanation of how to build a LEGO model or complete a map. He found that, compared to learners who were not given time to plan, the learners who planned produced longer utterances, and produced more grammatically complex speech.

Planning and preparation can be done individually, with the help of guide sheets or in groups. Before doing a same or different split information activity, for example, all the learners who are $A$ get together and work on what they will say. Similarly all the learners who are $B$ get together and plan and practise. After this has been done, the A's pair up with the B's to do the activity.

\section{Balancing the strands}

The four strands of a course should get roughly equal proportions of time. In making this calculation, time spent with the language outside the classroom must also be considered, but only if it meets the conditions for learning for a particular strand. That is, if a learner spends a lot of time watching TV, this could not be counted as much meaning-focused input if most of what is heard from the TV is not understood.

There could be small adjustments to the proportion of time according to the level of the students. For example, at the intermediate level about $20 \%$ of the class time could be given to language-focused instruction. This instruction might include pronunciation practice, vocabulary teaching and learning, grammar models and explanation, and feedback on speaking and writing performance. This would be less than in the beginning of the course where the learners needed more models, guidance and explanation. Later in the course, languagefocused instruction still has a useful role to play, although the time given to it would be less. In the advanced stages, there could be formal feedback on performance (especially to get over fossilisation), vocabulary expansion, and attention to discourse and sociolinguistic conventions.

Where there is little contact with the language outside the school, at the intermediate level, meaning-focused 
listening and reading input could be given about 30\% of the class time, meaning-focused speaking and writing about $20 \%$, and fluency activities about $30 \%$.

These last three strands become very difficult to distinguish from each other as learners' proficiency increases. This is because speaking activities involve others listening, group work inevitably involves a mixture of listening and speaking interaction, and fluency activities may also contribute to accuracy, the learning of language items, and discourse knowledge, as well as improving skill in use. It is probably not important to distinguish these three strands at advanced levels of proficiency. What is more important is to ensure that the learners are not getting too much of one strand at the expense of another.

This article is based on a book entitled Teaching Listening and Speaking that is in the draft stage.

\section{References}

Anderson, J.R. 1989. Practice, working memory, and the ACT* theory of skill acquisition: a comment on Carlson, Sullivan, and Schneider. Journal of Experimental Psychology: Learning Memory, and Cognition 15: 527-530.

Arevart, Supot \& Nation, I.S.P. 1991. Fluency improvement in a second language. RELC Journal $22,1: 84-94$.

Beebe, L.M. (ed.) 1988. Issues in Second Language Acquisition. New York: Newbury House.

Brumfit, C.J. 1984. Communicative methodology in language teaching: The roles of fluency and accuracy. Cambridge: Cambridge University Press.

Cheng, P.W. 1985. Restructuring versus automaticity: Alternative accounts of skill acquisition. Psychological Review 92: 414-423.

Crookes, G. 1989. Planning and interlanguage variation. Studies in Second Language Acquisition 11: 367-384.

Ellis, R. 1990. Instructed Second Language Acquisition. Oxford: Basil Blackwell.

— 1992. Learning to communicate in the classroom: A study of two language learners' requests. Studies in Second Language Acquisition $14: 1: 1-23$

1993. The structural syllabus and second language acquisition. TESOL Quarterly 27: 1:91-113.

Fotos, S. 1994. Integrating grammar instruction and communicative language use through grammar consciousness-raising tasks. TESOL Quarterly 28:2:323-351.

Gass, Susan M. and Madden, Carolyn G. (eds) 1985. Input in Second Language Acquisition. Mass: Newbury House.

Gregg, K.R. 1984. Krashen's monitor and Occam's razor. Applied Linguistics 5:79-100.

Griffiths, R. 1991. Pausological research in an L2 context: a rationale, and review of selected studies. Applied Linguistics 12:4:345-364.

Krashen, S.D. 1981. The fundamental pedogogical principle in second langauge teaching. Studia Linguistica 35:1-2:50-70.

Lennon, P. 1990. Investigating fluency in EFL: A quantitative approach. Language Learning. 40:3: 387-417.

Long, M. 1988. Instructed interlanguage development in Beebe, L. ed. 1988.

Maurice, K. 1983. The fluency workshop. TESOL Newsletter 17:4:29.

Nation, I.S.P. 1989. Improving speaking fluency. System 17:3:377-384.

Palmer, D.M. 1982. Information transfer for listening and reading. English Teaching Forum 20:1:29-33.

Schmidt, R. 1990. The role of consciousness in second language learning. Applied Linguistics 11:2: 129-158.

Schmidt, R. 1992. Psychological mechanisms underlying second language fluency. Studies in Second Language Acquisition 14:357-385.

Swain, M. 1985. Communicative competence: Some roles of comprehensible input and copmrehensible output in its development. In S.M. Gass and C.G. Madden 1985: 235-253.

Taylor, B.P. 1982. In search of real reality. TESOL Quarterly 161:28-42.

Terrell, T.D. 1982. The natural approach to language teaching: An update. Modern Language Journal 66:2:121-132.

Paul Nation is an Associate Professor at the English Language Institute in Victoria University of Wellington, New Zealand. He has taught in Indonesia, Thailand, the United States, Finland, and Japan. His specialist interests are language teaching methodology and vocabulary learning. 